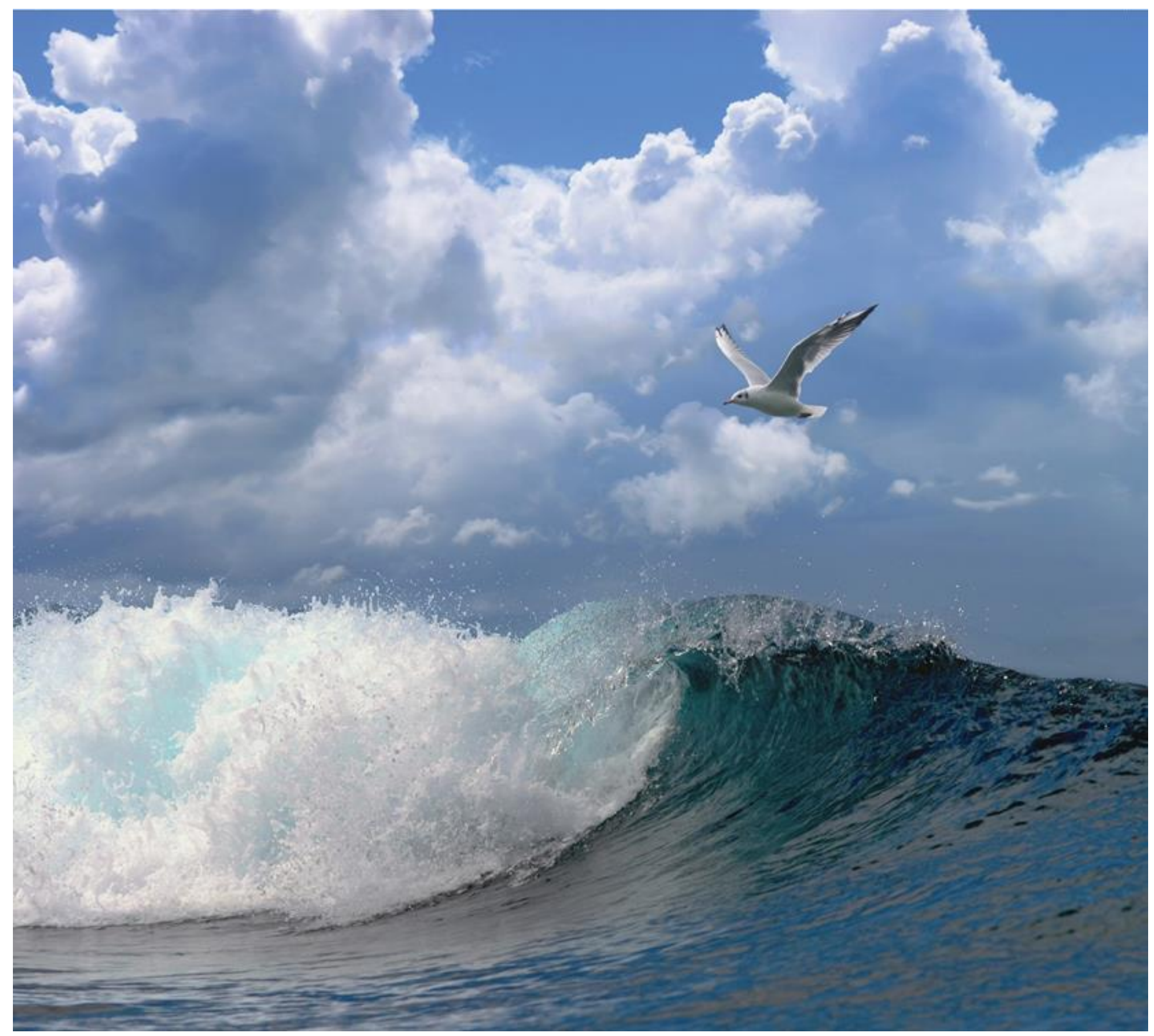

Actieve biologische Monitoring Zoete Rijkswateren: microverontreiniging in zoetwatermosselen 2017 


\section{Actieve biologische Monitoring Zoete Rijkswateren: microverontreinigingen in zoetwatermosselen 2017}

Biologische gegevens van MWTL Zoetwatermossel

RWS-rapport BM 18.04

Auteur(s): $\quad$ A.C. Sneekes \& E. van Barneveld

Publicatiedatum: 13 augustus 2018 
Sneekes A.C., E. van Barneveld, 2018. "Actieve biologische Monitoring Zoete Rijkswateren: microverontreinigingen in zoetwatermosselen 2017. Biologische gegevens van MWTL

Zoetwatermossel. RWS-rapport BM 18.04" Wageningen Marine Research Wageningen UR (University \& Research centre), Wageningen Marine Research rapport C050/18.

Opdrachtgever: Rijkswaterstaat Waterdienst

T.a.v.: M. Roos

Postbus 17

8200 AA Lelystad

Dit rapport is gratis te downloaden van https://doi.org/10.18174/455752

Wageningen Marine Research verstrekt geen gedrukte exemplaren van rapporten.

Wageningen Marine Research Wageningen UR is ISO 9001:2008 gecertificeerd.

(C) 2018 Wageningen Marine Research Wageningen UR

Wageningen Marine Research, onderdeel van Stichting Wageningen Research KvK nr. 09098104,

IMARES BTW nr. NL 8113.83.696.B16. Code BIC/SWIFT address: RABONL2U IBAN code: NL 73 RABO 0373599285
De Directie van Wageningen Marine Research is niet aansprakelijk voor gevolgschade, noch voor schade welke voortvloeit uit toepassingen van de resultaten van werkzaamheden of andere gegevens verkregen van Wageningen Marine Research opdrachtgever vrijwaart Wageningen Marine Research van aanspraken van derden in verband met deze toepassing.

Dit rapport is vervaardigd op verzoek van de opdrachtgever hierboven aangegeven en is zijn eigendom. Niets uit dit rapport mag weergegeven en/of gepubliceerd worden, gefotokopieerd of op enige andere manier gebruikt worden zonder schriftelijke toestemming van de opdrachtgever. 


\section{Inhoud}

$\begin{array}{lr}\text { Samenvatting } & 4\end{array}$

$1 \quad$ Inleiding $\quad 5$

2 Kennisvraag $\quad 6$

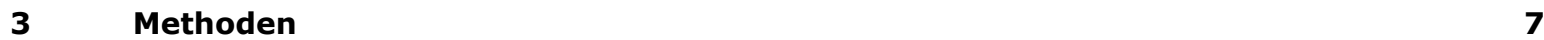

$\begin{array}{lll}3.1 & \text { Bemonstering zoetwatermosselen } & 7\end{array}$

3.2 Uitvoering ABM onderzoek $\quad 8$

$\begin{array}{ll}3.3 \text { Monsteropwerking } & 10\end{array}$

3.4 Analysemethoden $\quad 10$

3.4.1 Droge stof, as en asvrijdrooggewicht 11

$\begin{array}{lll}3.4 .2 & \text { Vet } & 11\end{array}$

3.4.3 Polycyclische aromatische koolwaterstoffen (PAK's) 11

3.5 Dataopslag en -registratie 11

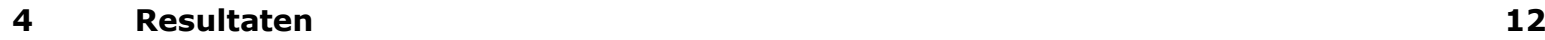

$\begin{array}{llr}5 & \text { Kwaliteitsborging } & 15\end{array}$

$\begin{array}{lr}\text { Verantwoording } & 16\end{array}$

Bijlagen rapport C050/18 ABM Schelpdieren zoet: 1 t/m 4.3 


\section{Samenvatting}

In het kader van de Monitoring chemische stoffen in Zoetwatermosselen is in 2017 de actieve biologische monitoring (ABM) uitgevoerd in zes zoete Rijkswateren. Dit project wordt in opdracht van Rijkswaterstaat van het Ministerie van Infrastructuur en Milieu uitgevoerd door Wageningen Marine Research te IJmuiden.

Op de referentielocatie Zeughoek zijn Quaggamosselen verzameld. Deze mosselen zijn, na verwerking tot uithangmonsters, bewaard in het laboratorium van Wageningen Marine Research tot de datum van uithangen op de onderzoeklocaties. Na afloop van de blootstellingsperiode van 42 tot 44 dagen is het gehalte aan microverontreinigingen in het mosselweefsel bepaald.

In dit rapport worden de analyseresultaten van het monitoringprogramma 2017 gerapporteerd. De volgende watersystemen zijn in 2017 bemonsterd:

1. IJsselmeer, Zeughoek (referentie locatie)

2. Grensmaas, Eijsden ponton (Maas Eijsden)

3. Bergsche Maas, Keizersveer (Maas Keizersveer)

4. Hollandse IJssel, Gouda voorhaven

5. Ketelmeer

6. Hollands Diep

De uitvoering van het project is succesvol verlopen; op alle locaties hebben de mosselen het uithangen overleefd en is voldoende mosselvlees verzameld voor analyse. De resultaten zijn in tabelvorm als bijlagen achter in dit rapport bijgevoegd en zijn tevens als DIF-file voor opslag in DONAR opgeleverd. 


\section{$1 \quad$ Inleiding}

Het Rijksinstituut voor Integraal Zoetwaterbeheer en Afvalwaterbehandeling (RIZA) van het Ministerie van Verkeer en Waterstaat is in 1992 gestart met de uitvoering van het monitoringprogramma "Biologische Monitoring Zoete Rijkswateren". Doelstellingen van de metingen zijn:

- $\quad$ het signaleren van langjarige ontwikkelingen in de biologische toestand van watersystemen (trend)

- $\quad$ periodieke toetsing van de toestand aan criteria die voortvloeien uit de toegekende functies van wateren (controle).

Een deelproject van de Biologische Monitoring Zoete Rijkswateren is "Microverontreinigingen in driehoeksmosselen (Dreissena polymorpha) ". In dit monitoringprogramma zijn de driehoeksmosselen in het veld inmiddels verdrongen door de Quaggamossel (Dreissena rostriformis bugensis). Om deze reden is vanaf 2011 overgegaan naar de Quaggamossel. Deze soort wordt ook verzameld op de locatie Zeughoek in het IJsselmeer.

De opdracht is gebaseerd op het document "Uitvraag tbv budgetbrief 2016-2017 en 2017-2018" ("de uitvraag"), van datum 23 maart 2017, en is uitgevoerd door Wageningen Marine Research. Op verschillende bemonsteringslocaties van het chemisch meetnet worden Quaggamosselen uit Zeughoek in het IJsselmeer uitgehangen in kooitjes en na 6 weken weer opgehaald en chemisch geanalyseerd op gehalte aan PAKs waarvoor KRW-biotanormen zijn afgeleid. De methode is beschreven in het projectplan Actieve monitoring chemische stoffen in zoetwatermosselen (MWTL zoetwatermossel). De bestaande monitoring is vanaf 2017 aangepast en volgt vanaf 2017 per locatie een driejaarlijkse cyclus, behalve in het waterlichaam Hollands diep (locatie Bovensluis) dat jaarlijks wordt gemeten. Dit rapport bevat de analyseresultaten van Quaggamosselen uit het onderzoek in 2017.

Vanuit RWS werd het programma geleid door mevr. A. Houben en vanuit Wageningen Marine Research fungeerde M. Kotterman als projectleider.

Bij Wageningen Marine Research te IJmuiden werden de organisch chemische analyses (PAK) en de analyses van vet, vocht en as uitgevoerd. 


\section{Kennisvraag}

In het kader van de hierboven genoemde opdracht werden door Wageningen Marine Research de volgende werkzaamheden uitgevoerd:

- $\quad$ Plannen van het onderzoek

- $\quad$ Ophalen van uitgangsmateriaal mosselen op de referentielocatie

- $\quad$ Uithangen en ophalen van de mosselen op diverse onderzoeklocaties

- $\quad$ Karakteriseren mosselen en verzamelen schelpdiervlees

- $\quad$ Het uitvoeren van chemische analyses

- $\quad$ Het rapporteren van de verkregen resultaten

- $\quad$ Het genereren van DONAR-files 


\section{Methoden}

\subsection{Bemonstering zoetwatermosselen}

Quaggamosselen, verzameld bij IJsselmeer-Zeughoek, zijn gebruikt als uitgangsmateriaal. Op 3 oktober 2017 zijn door RWS met behulp van een kornet de mosselen opgevist. De verzamelde mosselen zijn dezelfde dag vervoerd naar Wageningen Marine Research in IJmuiden. De Quaggamosselen zijn vervolgens gezeefd en gespoeld met water om stenen, zwanenmosselen, zand en ander ongewenst materiaal te verwijderen. Vanaf de dag van verzamelen tot het tijdstip van uithangen op de diverse locaties zijn de mosselen bewaard in een aquarium van Wageningen Marine Research in stromend, kopervrij leidingwater (watertemperatuur circa $12^{\circ} \mathrm{C}$; zuurstofgehalte $>9$ $\left.\mathrm{g} / \mathrm{m}^{3}\right)$.

De omschrijvingen van alle monsterlocaties in de Rijkswateren zijn vermeld in Tabel 1 en Figuur 1 geeft de ligging van de monsterlocaties aan van het monitoringonderzoek. De onderzoeklocaties worden niet elk jaar, maar in een cyclus van drie jaar bemonsterd met uitzondering van Hollands Diep. Deze locatie wordt jaarlijks bemonsterd en fungeert daarmee als referentie uithanglocatie.

In Tabel 1 wordt het bemonsteringsschema 2017 t/m 2023 weergegeven. De locaties waar de mosselen zijn uitgehangen in het najaar van 2017 zijn blauw gedrukt, de plaats van herkomst (referentiegebied IJsselmeer Zeughoek) en de jaarlijkse uithanglocatie zijn in zwart weergegeven.

Tabel $1 \quad$ Locaties en omschrijving ten behoeve van een actief biologische monitoring met zoetwatermosselen in Nederlandse oppervlaktewateren periode 2017-2023

\begin{tabular}{|c|c|c|c|}
\hline Watersysteem & DONAR code & DONAR omschrijving & Jaar \\
\hline $\begin{array}{l}\text { IJsselmeer (referentie, opvissen), } \\
\text { - voorkeur: Zeughoek }\end{array}$ & ZEUGHK & Zeughoek & alle \\
\hline $\begin{array}{l}\text { Hollands Diep, (referentie) } \\
\text { - voorkeur: Bovensluis, meerpaal nabij } \\
\text { Strijensas, } 2 \text { m uit kant }\end{array}$ & BOVSS & Bovensluis & alle \\
\hline $\begin{array}{l}\text { Grensmaas, Eijsden ponton, } \\
\text { - voorkeur: aan meetponton RWS }\end{array}$ & EIJSDPTN & Eijsden ponton & $2017,2020,2023$ \\
\hline $\begin{array}{l}\text { Bergsche Maas, Keizersveer, } \\
\text { - voorkeur: aan meetponton RWS }\end{array}$ & KEIZVR & Keizersveer & $2017,2020,2023$ \\
\hline $\begin{array}{l}\text { Hollandsche IJssel, Goudavoorhaven, } \\
\text { - voorkeur: meerpaal nabij sluis }\end{array}$ & GOUDVHVN & Gouda voorhaven & $2017,2020,2023$ \\
\hline $\begin{array}{l}\text { Ketelmeer, Ketelmeer-west, } \\
\text { - voorkeur: meerpaal of meetpaal }\end{array}$ & KETMWT & Ketelmeer west & $2017,2020,2023$ \\
\hline $\begin{array}{l}\text { Rijn / Bovenrijn, Lobith ponton, } \\
\text { - voorkeur: aan meetponton RWS }\end{array}$ & LOBPTN & Lobith ponton & 2018,2021 \\
\hline $\begin{array}{l}\text { Nieuwe Waterweg, Maassluis, } \\
\text { - voorkeur: meerpalen, } 2 \text { m uit kant, 3m } \\
\text { onder wateroppervlak }\end{array}$ & MAASSS & Maassluis & 2018,2021 \\
\hline $\begin{array}{l}\text { Noordzeekanaal, Amsterdam, } \\
\text { - voorkeur: meerpalen op } 4 \text { plaatsen in } \\
\text { Het IJ nabij CS, eiland en A'dam-Noord, } \\
\text { 2-3 m onder wateroppervlak }\end{array}$ & AMSDM & Amsterdam & 2018,2021 \\
\hline Twentekanaal, Eefde boven & EEFDBVN & Eefde boven & 2018,2021 \\
\hline $\begin{array}{l}\text { Volkerak / Zoommeer, Steenbergen, } \\
\text { (Roosendaalsevliet) } \\
\text { - voorkeur: meerpalen en beschoeiing } \\
\text { aan de westkant Volkerak }\end{array}$ & STEENBGN & Steenbergen & 2019, 2022 \\
\hline
\end{tabular}




\begin{tabular}{|l|l|l|l|}
\hline Watersysteem & DONAR code & DONAR omschrijving & Jaar \\
\hline $\begin{array}{l}\text { IJsselmeer, Vrouwezand, } \\
\text { - voorkeur: meetpaal FL9 in beheer van } \\
\text { CIV VM }\end{array}$ & VROUWZD & Vrouwezand & 2019, 2022 \\
\hline $\begin{array}{l}\text { Randmeren-oost, Wolderwijd, De Zegge, } \\
\text { - voorkeur: meerpalen bij eiland De } \\
\text { Zegge }\end{array}$ & DEZGE & $\begin{array}{l}\text { Randmeren-oost, } \\
\text { Wolderwijd, De Zegge }\end{array}$ & 2019, 2022 \\
\hline
\end{tabular}

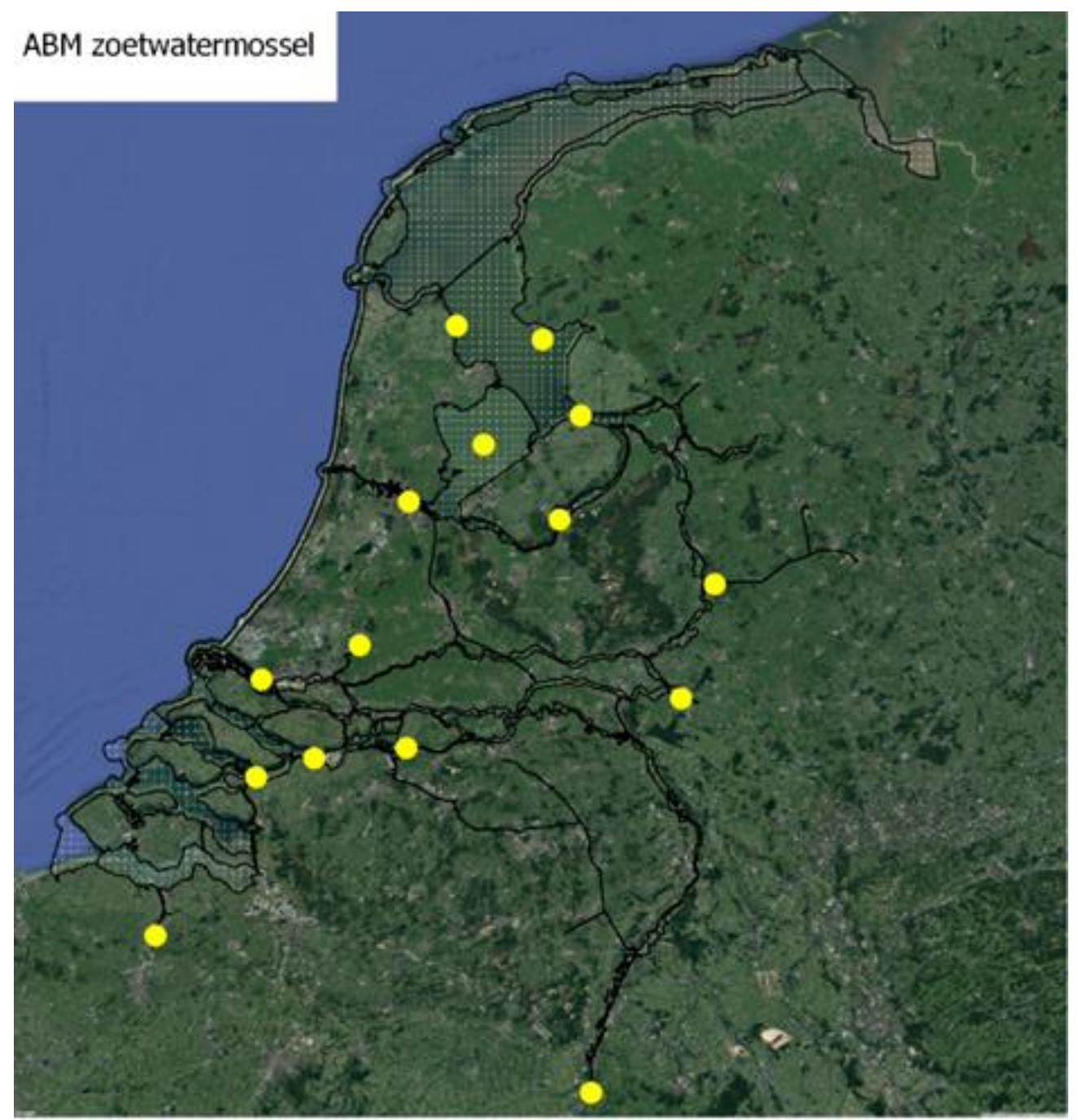

Figuur $1 \quad$ Ligging locaties biologische monitoring zoete Rijkswateren.

\subsection{Uitvoering ABM onderzoek}

De Quaggamosselen zijn op dezelfde manier op de onderzoeklocaties uitgehangen als in de voorgaande jaren. De mosselen zijn in twee in elkaar geschoven netjes (rekbaar kunststof garen) van $60 \mathrm{~cm}$ lengte, een diameter van omstreeks 10 à $15 \mathrm{~cm}$ en een maaswijdte van $9 \mathrm{~mm}$ uitgehangen. Elk netje bevatte circa $300 \mathrm{~g}$ mosselen. Onder- en bovenkant van de netjes zijn afgesloten door een knoop. In het midden van elk netje mosselen is vervolgens met behulp van stevig draad een insnoering gemaakt, zodat een saucijsvormig pakketje mosselen is verkregen. De netjes zijn vastgemaakt aan een koord met een onderlinge afstand van 20-30 cm (4 tot 5 -netjes per koord). Onderaan het koord werd een gewicht gehangen opdat de mosselen verticaal blijven hangen. Drie koorden zijn vervolgens opgehangen aan een meetpaal, meerpaal of ponton, afhankelijk van de situatie bij de te onderzoeken locatie (Figuur 2). De afstand van de waterbodem bedroeg afhankelijk van de locatie 0,5 tot $2 \mathrm{~m}$. 

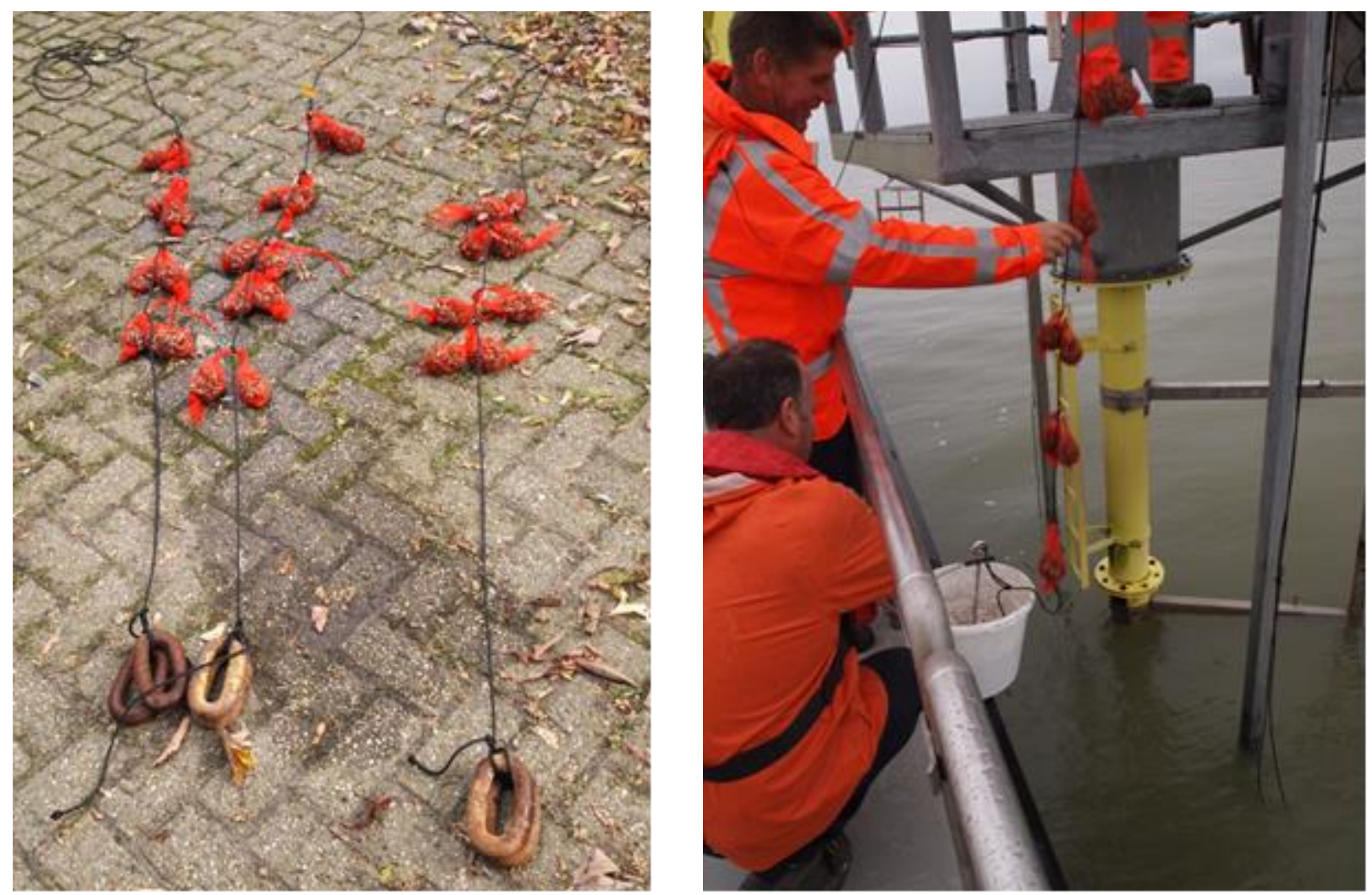

Figur 2 Voorbeelden van het uithangen van de mosselen. Bevestiging van de mosselen aan het koord (links) met schakels als gewichten, uithangen van een koord aan een meetpaal met een cementanker om het koord strak te houden (rechts).

Per locatie zijn 12-15 netjes met Quaggamosselen uitgehangen, wat neerkomt op 3,6-4,5 kg bruto mosselen. De netjes met Quaggamosselen zijn in de periode van 10-12 oktober 2017 op de diverse locaties uitgehangen. Deze najaarsperiode is bewust gekozen, omdat de paaiperiode (productie en afzetten van ei- en zaadcellen: gametogenese) dan is afgelopen en de overlast (storm, ijsgang) van herfst en winter nog gering is. De netjes zijn in de periode van 20 november tot 23 november weer opgehaald. De accumulatieduur wisselde van 42 dagen voor Maas Eijsden, Ketelmeer en Hollands Diep tot 44 dagen voor Hollandse IJssel (Tabel 2). Een aantal netjes met mosselen is niet uitgehangen, maar op 10 oktober in de vriezer opgeslagen om de uitgangssituatie (IJsselmeer-Zeughoek), inclusief verblijf in het doorstroomaquarium, vast te leggen.

Tabel 2 Overzicht van de accumulatieduur aangegeven per locatie van uitgehangen Quaggamosselen in 2017.

\begin{tabular}{|l|l|l|l|}
\hline WMR request nummer & WMR LIMS code & Locatie & Accumulatieduur \\
\hline RQ20171106/106 & $2017 / 2423$ & IJsselmeer Zeughoek & 0 \\
\hline RQ20171106/107 & $2017 / 2425$ & Maas Eijsden & 42 \\
\hline RQ20171106/108 & $2017 / 2427$ & Maas Keizersveer & 43 \\
\hline RQ20171106/109 & $2017 / 2429$ & Hollandse IJssel & 44 \\
\hline RQ20171106/110 & $2017 / 2431$ & Ketelmeer & 42 \\
\hline RQ20171106/111 & $2017 / 2433$ & Hollands Diep & 42 \\
\hline
\end{tabular}

Van elk opgehaald monster, waarbij geen volledige sterfte werd geconstateerd, is een submonster, overeenkomend met ongeveer $250 \mathrm{~g}$ bruto mosselen, genomen. Van dit submonster zijn de volgende parameters bepaald: aanwezige tarra (lege schelpen), het aantal levende en het aantal dode mosselen, het totale gewicht, het totale schelpgewicht en het totale vleesgewicht. Vervolgens zijn van elk monster nog meer mosselen gepeld tot er uiteindelijk voldoende vlees was verzameld voor de chemische analyses. Hiervoor zijn alleen de Quaggamosselen $>14 \mathrm{~mm}$ gebruikt. Ook dit jaar bestond het monster uit tamelijk kleine mosselen. 


\subsection{Monsteropwerking}

Per mosselmonster is een hoeveelheid mosselen gepeld tot een totaal van circa $125 \mathrm{~g}$ mosselweefsel (natgewicht) werd verkregen. Alleen het aanhangend mosselvocht is hierbij meegenomen. Het pellen is uitgevoerd in een speciale Contaminatie Arme Ruimte (CAR) met toevoer van gefilterde lucht. Dit om contaminatie van de monsters met PAK's te voorkomen. Het ruwe mosselmateriaal is tot een homogenaat verwerkt met behulp van een Ultra Turrax. Het homogenaat is vervolgens opgeslagen in een glazen pot voor analyse van organische microverontreinigingen. De potten zijn opgeslagen bij een temperatuur van $-25^{\circ} \mathrm{C}$ tot verdere analyse.

\subsection{Analysemethoden}

De chemische componenten die in de monitoringscyclus van 2017-2018 zijn geanalyseerd en gerapporteerd zijn opgenomen in Tabel 3. Ten opzichte van vorig jaar is de lijst verkort, nu worden alleen PAK's gemeten.

Tabel 3 Overzicht van de chemische componenten die zijn geanalyseerd en gerapporteerd inclusief bijbehorende naam zoals gebruikt in dit rapport, de DONAR-code en CASnummer.

\begin{tabular}{|l|l|l|l|}
\hline Component & Rapport & Donar-code & CAS-nummer \\
\hline $\begin{array}{l}\text { Accumulatieduur (dagen na } \\
\text { inhangdatum) }\end{array}$ & Accumulatieduur & ACCMLTDR & n.v.t. \\
\hline Gemiddeld vleesgewicht bovenmaats & Gemiddeld vleesgewicht & GEM_WGT & n.v.t. \\
\hline Gemiddelde lengte schelp bovenmaats & Gemiddelde lengte & GEM-LTE & n.v.t. \\
\hline Percentage droge stof & Droge stof \% & \%DS & n.v.t. \\
\hline Percentage gloeiverlies & AVDG & $\%$ GV & n.v.t. \\
\hline Percentage gloeirest & As & \%GR & n.v.t. \\
\hline Vet: totaal B\&D & Vet B\&D & VET & n.v.t. \\
\hline Benzo(b)fluoranteen & Benzo(b)fluoranteen & BbF & $205-99-2$ \\
\hline Benzo(k)fluoranteen & Benzo(k)fluoranteen & BkF & $207-08-9$ \\
\hline Fluoranteen & Fluoranteen & Flu & $206-44-0$ \\
\hline Benzo(a)pyreen & Benzo(a)pyreen & BaP & $50-32-8$ \\
\hline Benzo(g,h,i)peryleen & Benzo(g,h,i)peryleen & BghiPe & $191-24-2$ \\
\hline Indeno(1,2,3-c,d)pyreen & Indeno(1,2,3-c,d)pyreen & InP & $193-39-5$ \\
\hline Fenanthreen & Fenanthreen & Fen & $85-01-8$ \\
\hline Anthraceen & Anthraceen & Ant & $120-12-7$ \\
\hline Benzo(a)anthraceen & Benzo(a)anthraceen & BaA & $56-55-3$ \\
\hline Chryseen & Chryseen & Chr & $218-01-9$ \\
\hline Pyreen & Pyreen & Pyr & $129-00-0$ \\
\hline Dibenzo(a,h)anthraceen & Dibenzo(a,h)anthraceen & DBahAnt & $53-70-3$ \\
\hline Acenafteen & Acenafteen & AcNe & $83-32-9$ \\
\hline Fluoreen & Fluoreen & Fle & $86-73-7$ \\
\hline
\end{tabular}

In paragraaf 3.4.1 t/m 3.4.3 wordt een korte beschrijving en een verwijzing naar de Interne Standaard Werkvoorschriften (ISW's) gegeven die gebruikt zijn voor de uitvoering van de chemische analyses. 


\subsubsection{Droge stof, as en asvrijdrooggewicht}

Voor de bepaling van het droge stofgehalte werd het gewogen monster gemengd met een oppervlakte vergrotende stof, vervolgens gedroogd in een stoof $\left(105^{\circ} \mathrm{C}, 3 \mathrm{uur}\right)$ en na afkoelen in een exsiccator teruggewogen.

De methode is vastgelegd in Wageningen Marine Research ISW 2.10.3.011 "Dierlijk weefsel. Bepalen van het gehalte aan vocht; gravimetrie" staat op de scope van de Raad voor Accreditatie onder testlaboratoriumnummer L097, verrichting nummer 2.

Voor de asbepaling werd het monster langzaam verwarmd en gedroogd in een kroes op een kookplaat. Daarna werd het monster gedurende 22 uur verast in een moffeloven bij een temperatuur van $550 \pm 15^{\circ} \mathrm{C}$. Na afkoelen in een exsiccator is het monster teruggewogen.

De methode is vastgelegd in Wageningen Marine Research ISW 2.10.3.018 "Dierlijk weefsel. Bepalen van het gehalte aan as; gravimetrie" en staat op de scope van de Raad voor Accreditatie onder testlaboratoriumnummer L097, verrichting nummer 4 .

Het percentage asvrijdrooggewicht wordt berekend uit het gehalte droge stof en as.

\subsubsection{Vet}

De totaal vet bepaling werd uitgevoerd volgens een aangepaste versie van de Bligh and Dyer methode, gebaseerd op een koude chloroform-methanol extractie.

De methode is vastgelegd in Wageningen Marine Research ISW 2.10.3.002 "Dierlijk weefsel. Bepalen van het gehalte aan vet volgens Bligh and Dyer; gravimetrie" en staat op de scope van de Raad voor Accreditatie onder testlaboratoriumnummer L097, verrichting nummer 1.

\subsubsection{Polycyclische aromatische koolwaterstoffen (PAK's)}

PAK's werden vrijgemaakt uit het monster door onder reflux te extraheren met methanolische kaliumhydroxide. Na extraheren met hexaan werd het verkregen extract gezuiverd over een silicagelaluminiumoxide-kolom. Van het gezuiverde extract is hexaan afgedampt onder toevoeging van acetonitril. De PAK's, in acetonitril, werden in een hogedrukvloeistofchromatograaf gescheiden en gedetecteerd door een fluorescentiemeter. Er werden twee aparte programma's gedraaid om alle PAKs goed te kunnen scheiden én detecteren met fluorescentie.

De methode is vastgelegd in Wageningen Marine Research ISW 2.10.3.005 "Schaal- en Schelpdieren. Bepalen van het gehalte aan polycyclische aromatische koolwaterstoffen (PAK) na extractie; HPLC met fluorescentiedetectie" en staat op de scope van de Raad voor Accreditatie onder testlaboratoriumnummer L097, verrichting nummer 15.

\subsection{Dataopslag en -registratie}

De gegenereerde data werden opgeslagen in LIMS. Een DONAR-script is beschikbaar dat ervoor zorgt dat de gegevens uit LIMS op de juiste manier in een DONAR-file terecht komen. De analyseresultaten uit het meetrapport die in LIMS zijn geïmporteerd, werden gecontroleerd door een andere analist die bevoegd is voor de uitvoering van betreffende bepaling dan de uitvoerend analist. De Exceltabellen die uit LIMS zijn gegenereerd en in het rapport zijn opgenomen, werden door de uitvoerende analisten gecontroleerd op eventuele fouten en geparafeerd voor vrijgave. Van elk analyseresultaat is beoordeeld of het voldoet aan de kwaliteitscriteria die zijn genoemd in het betreffende ISW, indien dit niet het geval was is de reden daarvan in het rapport vermeld. 


\section{Resultaten}

De resultaten vermeld in dit rapport zijn alleen van toepassing op de geanalyseerde monsters. De chemische analyses hebben plaatsgevonden in de periode van november $2017 \mathrm{t} / \mathrm{m}$ april 2018 in het laboratorium van Wageningen Marine Research locatie IJmuiden.

De verzamelde gegevens en analyse-uitkomsten zijn in tabelvorm weergegeven in de bijlagen van dit rapport en zullen volgens opdracht tevens als Excel spreadsheet elektronisch worden verzonden. Een beschrijving van de bijlagen is weergegeven in Tabel 4.

De analyse-uitkomsten en bijbehorende biologische gegevens van de Quaggamosselen zijn tevens als DIF-file voor opslag in DONAR opgeleverd.

Tabel 4 Beschrijving van de Bijlagen

\begin{tabular}{|l|l|}
\hline Bijlage & Titel \\
\hline Bijlage 1 & $\begin{array}{l}\text { ABM Schelpdieren zoet 2017 / Bijlage 1: Gehalten Biochemische parameters } \\
\text { Quaggamosselen (onderzoek najaar 2017). }\end{array}$ \\
\hline Bijlage 2 & $\begin{array}{l}\text { ABM Schelpdieren zoet 2017 / Bijlage 2: Gehalten PAKs in Quaggamosselen } \\
\text { (onderzoek najaar 2017). }\end{array}$ \\
\hline Bijlage 3 & $\begin{array}{l}\text { ABM Schelpdieren zoet 2017 / Bijlage 3: Biologische gegevens in Quaggamosselen } \\
\text { (onderzoek najaar 2017). }\end{array}$ \\
\hline Bijlage 4.1 & $\begin{array}{l}\text { ABM Schelpdieren zoet 2017 / Bijlage 4.1: Validatiegegevens analysemethoden / } \\
\text { Resultaten referentiematerialen }\end{array}$ \\
\hline Bijlage 4.2 & $\begin{array}{l}\text { ABM Schelpdieren zoet 2017 / Bijlage 4.2: Validatiegegevens analysemethoden / } \\
\text { Resultaten Ringonderzoek Quasimeme in biota }\end{array}$ \\
\hline Bijlage 4.3 & $\begin{array}{l}\text { ABM Schelpdieren zoet 2017 / Bijlage 4.3: Validatiegegevens analysemethoden / } \\
\text { Rapportagegrenzen en meetonzekerheid }\end{array}$ \\
\hline
\end{tabular}

Ten aanzien van de resultaten van Wageningen Marine Research kan opgemerkt worden dat ze voldoen aan de kwaliteitseisen, zoals genoemd in 5 Kwaliteitsborging. Wel is een afwijking van de kwaliteitscriteria geconstateerd voor het geaccrediteerde component benzo(b)fluoranteen. De afwijking betrof enkel voor de monsters met code 2017/2428 en 2017/2432. Hier werd een verschuiving van de retentietijd in de tweede run geconstateerd waardoor de gehalten van deze monsters niet correct bepaald konden worden. De gehalten van de eerste run, die wel goed verlopen was, is gebruikt voor de rapportage, maar worden niet met het kwaliteitskenmerk Q gerapporteerd en zijn als indicatieve waarden (kwaliteitswaardecode 4) opgegeven.

De resultaten van de IRM's, gemeten door Wageningen Marine Research, zijn gecontroleerd met betrekking tot overschrijdingen van de 2s- en 3s-grenzen van de door Wageningen Marine Research intern gehanteerde kwaliteitscontrolekaarten voor de betreffende elementen. Dit is weergegeven in Bijlage 4.1. Indien de 3s-grens wordt overschreden wordt daarop, vastgelegd in ons kwaliteitssysteem, adequaat actie ondernomen. Bijlage 4.1 toont dat aan de metingen in de IRM's, in 2017 uitgevoerd door Wageningen Marine Research, de kwalificatie goed kan worden toegekend.

In Bijlage 4.2 zijn de resultaten van deelname aan Quasimeme ringonderzoeken weergegeven (de labcode van Wageningen Marine Research is Q127). Indien een z-score de kwalificatie 'unsatisfactory' heeft gekregen wordt daarop, vastgelegd in ons kwaliteitssysteem, adequaat actie ondernomen. Hierop vindt jaarlijks controle plaats door de Raad voor Accreditatie. 
De betekenissen van de kwalificaties, zoals door Quasimeme toegekend, zijn als volgt:

Satisfactory:

Unsatisfactory:

Questionable:

Consistent:

Inconsistent:

Blanc:
$|Z|<2$, resultaat voldoet

$|Z|>3$, resultaat voldoet niet (adequate actie vereist)

$|Z|<3$, resultaat is twijfelachtig (geen actie vereist)

er is een waarde $(x)<$ rapportagegrens door het deelnemend lab

gerapporteerd, deze waarde was in overeenstemming met de assigned value (consensus waarde), bv. $<0.03$ gerapporteerd, terwijl assigned value 0.02 is er is een waarde $(x)<$ rapportagegrens door het deelnemend lab gerapporteerd, deze waarde was niet in overeenstemming met de assigned value (consensus waarde), bv. $<0.03$ gerapporteerd, terwijl assigned value 0.06 is

geen z-score bepaald door Quasimeme (mogelijke oorzaken: te weinig laboratoria hebben resultaten gerapporteerd of de spreiding van de resultaten tussen de laboratoria onderling was te groot)

Bijlage 4.2 laat voor de PAK-analyse de resultaten van de ringonderzoeken in 2016 en 2017 zien. In 2017 werd niet officieel deelgenomen aan ringonderzoekrondes van Quasimeme deelgenomen; de monsters voor de ringtesten zijn wel gemeten in 2017, maar door defect van de apparatuur waren de resultaten te laat verkregen waardoor de inlevertermijn voor indienen was verstreken. De genoteerde Z-scores van 2017 zijn achteraf berekend op basis van de resultaten van het ringonderzoek.

In 2016 werd in totaal drie keer de kwalificatie unsatisfactory toegekend, betreffende de componenten dibenz(ah)antraceen, benzo(a)pyreen en indeno(123-cd)pyreen. Dibenzo(ah)antraceen staat niet op de scope en deze resultaten worden daarom zonder Q gerapporteerd. Benzo(a)pyreen werd sindsdien nauwlettend in de gaten gehouden, maar omdat de overige controles voldeden aan de gestelde eisen en de vergelijking van de resultaten uit de ringtest in 2017 binnen de gestelde eisen viel wordt deze stof onder Q gerapporteerd. Specifiek voor indeno(123-cd)pyreen betrof het een probleem met de blanco in 2016, welke in de periode erna opgelost is. De resultaten van de ringtest in 2017 bevestigen dat het probleem met de blanco bij indeno(123-cd)pyreen niet meer aanwezig is. De resultaten van indeno(123-cd)pyreen worden daarom ook onder Q gerapporteerd.

In Bijlage 4.3 zijn de rapportagegrenzen en meetonzekerheden weergegeven. Hierover kan het volgende worden vermeld:

De rapportagegrenzen voor de anorganische componenten en voor de metalen zijn vaste grenzen die zijn vastgesteld uit de historie van de blanco bepalingen.

De rapportagegrenzen voor de organische componenten worden vastgesteld aan de hand van de laagst gemeten standaard. De rapportagegrens is afhankelijk van de hoeveelheid ingewogen monster en is dus eigenlijk voor ieder monster verschillend, de compromis rapportagegrenzen zijn in Bijlage 4.3 weergegeven.

De meetonzekerheid wordt door WMR volgens NEN7779 bepaald, met RMS (root mean square) als uitgangspunt. Hierbij wordt uit de standaardonzekerheid de uitgebreide (meet)onzekerheid berekend. Dit is het $95 \%$ betrouwbaarheidsinterval dat in de meetwaarden gebruikt wordt.

Als basis voor de bepaling van de meetonzekerheid als relatieve waarde met interne laboratoriumgegevens en met de berekening RMS als uitgangspunt zijn er drie mogelijkheden:

1. Ringonderzoek (afgedekt zijn: reproduceerbaarheid, juistheid en tussen-monsterspreiding)

2. CRM (afgedekt zijn reproduceerbaarheid en juistheid)

3. Terugvinding (afgedekt zijn reproduceerbaarheid en juistheid)

Door de selectie van de gegevensbronnen zijn de vereiste parameters reproduceerbaarheid, gemiddelde methode-juistheid, tussen-monsterspreiding en monsterinhomogeniteit zo goed mogelijk afgedekt. 
De volgende formule uit NEN7779 wordt hiervoor gebruikt:

$$
U_{r e l}=2 u_{r e l}=2 R M S_{r e l}=2 \sqrt{\frac{1}{n} \sum_{i=1}^{n}\left(\frac{y_{i}-\mu_{i}}{\mu_{i}}\right)^{2}}
$$

Waarin:

$U_{\text {rel }} \quad$ uitgebreide relatieve (meet)onzekerheid, in \%

$u_{r e l} \quad$ relatieve standaardonzekerheid, in \%

$R M S_{\text {rel }}$ relatieve Root Mean Square, in \%

$n \quad$ aantal $(n \geq 8)$

$y_{i} \quad$ meetresultaat

$\mu_{i} \quad$ (conventioneel) ware waarde

Voor de rapportage aan OSPAR door RWS wordt het 95\% betrouwbaarheidsinterval van de meetwaarde aangeleverd. Dit is de $U_{\text {rel }}$ uit bovenstaande formule. OSPAR gebruikt hiervoor echter een $U_{\text {c }}$ (de absolute uitgebreide meetonzekerheid, in eenheid van concentratie component), berekend op basis van de volgende twee formules uit de OSPAR guideline:

$$
S_{\mathrm{c}}=\sqrt{d_{\mathrm{c}}^{2}+\left(\frac{v c}{100}\right)^{2}} C^{2}
$$

waarin:

$s_{c} \quad$ standaarddeviatie, in eenheid van concentratie component

$d_{\mathrm{c}} \quad$ gecombineerde constante fout, in eenheid van concentratie component

$v c \quad$ variatiecoëfficiënt, in \%

C concentratie van de component in het monster (meetwaarde)

$$
U_{\mathrm{c}}=2 s_{\mathrm{c}}
$$

waarin:

$U_{c} \quad$ absolute uitgebreide (meet)onzekerheid, in eenheid van concentratie component

$s_{c} \quad$ standaarddeviatie, in eenheid van concentratie component

In Bijlage 4.3 worden de vereiste parameters voor deze OSPAR-berekening getoond. 


\section{$5 \quad$ Kwaliteitsborging}

Wageningen Marine Research beschikt over een ISO 9001:2008 gecertificeerd kwaliteitsmanagementsysteem (certificaatnummer: 187378-2015-AQ-NLD-RvA). Dit certificaat is geldig tot 15 september 2018. De organisatie is gecertificeerd sinds 27 februari 2001. De certificering is uitgevoerd door DNV Certification B.V.

Het chemisch laboratorium te IJmuiden beschikt over een NEN-EN-ISO/IEC 17025:2005 accreditatie voor testlaboratoria met nummer L097. Deze accreditatie is geldig tot 1 april 2021 en is voor het eerst verleend op 27 maart 1997; deze accreditatie is verleend door de Raad voor Accreditatie. Het chemisch laboratorium heeft hierdoor aangetoond in staat te zijn op technisch bekwame wijze valide resultaten te leveren en te werken volgens de ISO17025 norm. De scope (L097) met de geaccrediteerde analysemethoden is te vinden op de website van de Raad voor Accreditatie (www.rva.nl).

Op grond van deze accreditatie is het kwaliteitskenmerk $\mathrm{Q}$ toegekend aan de resultaten van die componenten die op de scope staan vermeld, mits aan alle kwaliteitseisen is voldaan. Het kwaliteitskenmerk Q staat vermeld in de tabellen met de onderzoeksresultaten. Indien het kwaliteitskenmerk $Q$ niet staat vermeld is de reden hiervan vermeld.

De kwaliteit van de analysemethoden wordt op verschillende manieren gewaarborgd. De juistheid van de analysemethoden wordt regelmatig getoetst door deelname aan ringonderzoeken waaronder die georganiseerd door QUASIMEME. Indien geen ringonderzoek voorhanden is, wordt een tweede lijnscontrole uitgevoerd. Tevens wordt bij iedere meetserie een eerstelijnscontrole uitgevoerd. Naast de lijncontroles wordende volgende algemene kwaliteitscontroles uitgevoerd:

- Blanco onderzoek.

- Terugvinding (recovery).

- Interne standaard voor borging opwerkmethode.

- Injectie standard.

- Gevoeligheid.

Indien sprake is van onbeheerste kwaliteit worden passende maatregelen genomen.

Bovenstaande controles staan beschreven in Wageningen Marine Research werkvoorschrift ISW 2.10.2.105.

Indien gewenst kunnen gegevens met betrekking tot de prestatiekenmerken van de analysemethoden bij het chemisch laboratorium worden opgevraagd. 


\section{Verantwoording}

Rapport C050/18

Projectnummer: 4316100090

Dit rapport is met grote zorgvuldigheid tot stand gekomen. De wetenschappelijke kwaliteit is intern getoetst door een collega-onderzoeker en het verantwoordelijk lid van het managementteam van Wageningen Marine Research

Akkoord:

Dr. Ir. M.J.J. Kotterman

Senior Onderzoeker

Handtekening:

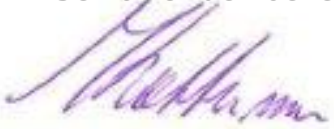

Datum:

13 augustus 2018

Akkoord:

Drs. J. Asjes

Manager integratie

Handtekening:

Datum: 


\section{Bijlagen rapport C050/18 ABM Schelpdieren zoet: $1 \mathrm{t} / \mathrm{m} 4.3$}


ABM Schelpdieren zoet 2017 / Bijlage 1: Gehalten Biochemische parameters in Quaggamosselen (onderzoek najaar 2017).

\begin{tabular}{|l|l|c|c|c|c|}
\hline LIMS code & Lokatie & $\begin{array}{c}\text { Droge stof } \\
\%\end{array}$ & $\begin{array}{c}\text { Asvrijdrooggewicht } \\
\%\end{array}$ & $\begin{array}{c}\text { As } \\
\% \\
\text { Q }\end{array}$ & $\begin{array}{c}\text { Vet(BD) } \\
\text { g/kg } \\
Q\end{array}$ \\
\hline $2017 / 2424$ & IJsselmeer Zeughoek & 3.2 & 2.8 & 0.4 & 3 \\
\hline $2017 / 2426$ & Maas Eijsden & 3.6 & 3.0 & 0.6 & 3 \\
\hline $2017 / 2428$ & Maas Keizersveer & 3.6 & 3.0 & 0.6 & 3 \\
\hline $2017 / 2430$ & Hollandse IJssel & 2.9 & 2.5 & 0.4 & 2 \\
\hline $2017 / 2432$ & Ketelmeer & 3.0 & 2.7 & 0.3 & 2 \\
\hline $2017 / 2434$ & Hollands Diep & 3.4 & 3.1 & 0.3 & 3 \\
\hline
\end{tabular}


ABM Schelpdieren zoet 2017 / Bijlage 2: Gehalten PAKs in Quaggamosselen (onderzoek najaar 2017).

\begin{tabular}{|l|c|c|c|c|c|c|c|}
\cline { 3 - 7 } \multicolumn{1}{l|}{} & & $\begin{array}{c}2017 / 2424 \\
\text { IJsselmeer } \\
\text { Zeughoek }\end{array}$ & $\begin{array}{c}2017 / 2426 \\
\text { Maas } \\
\text { Eijsden }\end{array}$ & $\begin{array}{c}2017 / 2428 \\
\text { Maas } \\
\text { Keizersveer }\end{array}$ & $\begin{array}{c}2017 / 2430 \\
\text { Hollandse } \\
\text { IJssel }\end{array}$ & $\begin{array}{c}2017 / 2432 \\
\text { Ketelmeer }\end{array}$ & $\begin{array}{c}2017 / 2434 \\
\text { Hollands } \\
\text { Diep }\end{array}$ \\
\hline Acenafteen & $\mathrm{Q}$ & 0.5 & 1.1 & 1.3 & 1.4 & 1.0 & 1.2 \\
\hline Fluoreen & $\mathrm{Q}$ & $<0.2$ & 0.7 & 0.3 & 0.9 & 0.3 & $<0.2$ \\
\hline Fenantreen & $\mathrm{Q}$ & $<1.8$ & 6.7 & 2.4 & 5.0 & 1.8 & $<1.8$ \\
\hline Anthraceen & $\mathrm{Q}$ & $<0.1$ & 1.0 & 0.4 & 1.4 & 0.4 & 0.3 \\
\hline Fluoranteen & $\mathrm{Q}$ & $<0.9$ & 19 & 7.8 & 16 & 4.3 & 4.1 \\
\hline Pyreen & $\mathrm{Q}$ & $<0.7$ & 20 & 8.6 & 20 & 4.8 & 5.0 \\
\hline Benzo(a)anthraceen & $\mathrm{Q}$ & $<0.1$ & 9.7 & 3.5 & 10 & 2.4 & 2.4 \\
\hline Chryseen & $\mathrm{Q}$ & $<0.3$ & 12 & 4.8 & 12 & 3.3 & 3.9 \\
\hline Benzo(b)fluoranteen & $\mathrm{Q}$ & 0.2 & 13 & 5.1 & 11 & 3.6 & 3.1 \\
\hline Benzo(k)fluoranteen & $\mathrm{Q}$ & $<0.1$ & 6.9 & 2.8 & 1.8 & 2.0 & 0.6 \\
\hline Benzo(a)pyreen & $\mathrm{Q}$ & $<0.1$ & 9.9 & 3.7 & 8.5 & 2.9 & 2.0 \\
\hline Dibenz(a,h)anthraceen & & $<0.3$ & $<0.3$ & $<0.3$ & $<0.4$ & $<0.3$ & $<0.3$ \\
\hline Benzo(g,h,i)peryleen & $\mathrm{Q}$ & $<0.1$ & 5.5 & 2.1 & 0.3 & 1.5 & 1.0 \\
\hline Indeno(1,2,3-cd)pyre & $\mathrm{Q}$ & 0.2 & 7.5 & 2.6 & 4.5 & 1.9 & 1.1 \\
\hline
\end{tabular}

$\mathrm{nb}=$ niet bepaald, kwaliteitswaardecode 99

indicatief, kwaliteitswaardecode 4 
ABM Schelpdieren zoet 2017 I Bijlage 3: Biologische gegevens in Quaggamosselen (onderzoek najaar 2017).

\begin{tabular}{|l|l|c|c|c|}
\hline LIMS code & Lokatie & Accumulatieduur & Gem. Vleesgew. & $\begin{array}{l}\text { Gem Lengte } \\
\text { Schelp }\end{array}$ \\
\hline $2017 / 2423$ & IJsselmeer Zeughoek & 0 & 0.12 & 16.3 \\
\hline $2017 / 2425$ & Maas Eijsden & 42 & 0.10 & 15.9 \\
\hline $2017 / 2427$ & Maas Keizersveer & 43 & 0.09 & 16.0 \\
\hline $2017 / 2429$ & Hollandse IJssel & 44 & 0.11 & 16.1 \\
\hline $2017 / 2431$ & Ketelmeer & 42 & 0.10 & 15.7 \\
\hline $2017 / 2433$ & Hollands Diep & 42 & 0.08 & 15.7 \\
\hline
\end{tabular}


Resultaten referentiematerialen

\begin{tabular}{|c|c|c|c|c|c|c|c|c|c|}
\hline $\begin{array}{l}\text { Chem. } \\
\text { groep }\end{array}$ & Component & $\begin{array}{l}\text { Referentie- } \\
\text { materiaal }\end{array}$ & $\begin{array}{l}\text { WMR-waarde } \\
\text { in } 2017 \\
\end{array}$ & $\begin{array}{c}n \\
\text { in } 2017 \\
\end{array}$ & $\begin{array}{c}\text { WMR-waarde } \\
\text { QC-kaart }\end{array}$ & $\begin{array}{c}n \\
\text { totaal }\end{array}$ & $\begin{array}{c}\text { gecertificeerde } \\
\text { waarde }\end{array}$ & eenheid & kwalificatie \\
\hline- & Ash-Weight & $\begin{array}{l}\text { IRM 2002/0757 } \\
\text { Mosselen }\end{array}$ & $1.58 \pm 0.04$ & (1) & $1.58 \pm 0.04$ & 97 & n.v.t. & $\%$ & goed \\
\hline- & Dry-weight & $\begin{array}{l}\text { IRM 2005/0775 } \\
\text { Haring/makreel }\end{array}$ & $69.93 \pm 0.29$ & 13 & $70.00 \pm 0.249$ & 268 & n.v.t. & $\%$ & goed \\
\hline- & Total-Lipid & $\begin{array}{l}\text { IRM 2005/0775 } \\
\text { Haring/makreel }\end{array}$ & $11.49 \pm 0.15$ & 14 & $11.53 \pm 0.14$ & 198 & n.v.t. & $\%$ & goed \\
\hline PAK & Benzo(b)fluoranteen & IRM 682 & 12 & 4 & $13.5 \pm 1.95$ & 19 & n.v.t. & $\mu \mathrm{g} / \mathrm{kg}$ & goed \\
\hline PAK & Benzo(ghi)peryleen & IRM 682 & 6 & 4 & $6.4 \pm 1.15$ & 19 & n.v.t. & $\mu \mathrm{g} / \mathrm{kg}$ & goed \\
\hline PAK & Fluoranteen & IRM 682 & 39 & 4 & $36.6 \pm 2.56$ & 18 & n.v.t. & $\mu \mathrm{g} / \mathrm{kg}$ & goed \\
\hline PAK & Indeno(1,2,3-cd)pyreen & IRM 682 & 7.5 & 4 & $6.9 \pm 0.80$ & 18 & n.v.t. & $\mu \mathrm{g} / \mathrm{kg}$ & goed \\
\hline PAK & Pyreen & IRM 682 & 32 & 4 & $27.2 \pm 3.18$ & 19 & n.v.t. & $\mu \mathrm{g} / \mathrm{kg}$ & goed \\
\hline
\end{tabular}




\begin{tabular}{|c|c|c|c|c|c|c|c|c|c|c|}
\hline Groep & Ronde & Periode & Matrix & $\begin{array}{l}\text { Chem. } \\
\text { groep }\end{array}$ & Component & Eenheid & Z-score & Qualificatie & Opmerking & accreditatie \\
\hline BT1 & 2016.01 & april 2016 & QTM110BT & - & Ash-Weight & $\%$ & -0.3 & Satisfactory & Quasimeme & ja \\
\hline BT1 & 2017.01 & apr 2017 & QTM112BT & - & Dry-weight & $\%$ & 0.0 & Satisfactory & Quasimeme & ja \\
\hline BT1 & 2017.01 & apr 2017 & QTM113BT & - & Dry-weight & $\%$ & -0.2 & Satisfactory & Quasimeme & ja \\
\hline BT1 & 2017.02 & nov 2017 & QTM114BT & - & Dry-weight & $\%$ & -0.3 & Satisfactory & Quasimeme & ja \\
\hline BT1 & 2017.02 & nov 2017 & QTM115BT & - & Dry-weight & $\%$ & -0.4 & Satisfactory & Quasimeme & ja \\
\hline BT1 & 2017.01 & apr 2017 & QTM112BT & - & Total-Lipid & $\%$ & 0.0 & Satisfactory & Quasimeme & ja \\
\hline BT1 & 2017.01 & apr 2017 & QTM114BT & - & Total-Lipid & $\%$ & 1.4 & Satisfactory & Quasimeme & ja \\
\hline BT1 & 2017.02 & nov 2017 & QTM115BT & - & Total-Lipid & $\%$ & 0.0 & Satisfactory & Quasimeme & ja \\
\hline BT1 & 2017.02 & nov 2017 & QTM117BT & - & Total-Lipid & $\%$ & 0.1 & Satisfactory & Quasimeme & ja \\
\hline BT4 & 2016.02 & nov 2016 & QPH083BT & PAK & Acenafteen & $\mu \mathrm{g} / \mathrm{kg}$ & 1.1 & Satisfactory & Quasimeme & ja \\
\hline BT4 & 2016.02 & nov 2016 & QPH083BT & PAK & Antraceen & $\mu \mathrm{g} / \mathrm{kg}$ & 1.4 & Satisfactory & Quasimeme & ja \\
\hline BT4 & 2016.02 & nov 2016 & QPH084BT & PAK & Antraceen & $\mu \mathrm{g} / \mathrm{kg}$ & 2 & Satisfactory & Quasimeme & ja \\
\hline BT4 & 2016.02 & nov 2016 & QPH083BT & PAK & Benzo(a)antraceen & $\mu \mathrm{g} / \mathrm{kg}$ & 1.7 & Satisfactory & Quasimeme & ja \\
\hline BT4 & 2016.02 & nov 2016 & QPH084BT & PAK & Benzo(a)antraceen & $\mu \mathrm{g} / \mathrm{kg}$ & 2 & Satisfactory & Quasimeme & ja \\
\hline BT4 & 2016.02 & nov 2016 & QPH083BT & PAK & Benzo(a)pyreen & $\mu \mathrm{g} / \mathrm{kg}$ & 1.8 & Satisfactory & Quasimeme & ja \\
\hline BT4 & 2016.02 & nov 2016 & QPH084BT & PAK & Benzo(a)pyreen & $\mu \mathrm{g} / \mathrm{kg}$ & 3.2 & Unsatisfactory & Quasimeme & ja \\
\hline BT4 & 2016.02 & nov 2016 & QPH084BT & PAK & Benzo(b)fluoranteen & $\mu \mathrm{g} / \mathrm{kg}$ & 2.4 & Questionable & Quasimeme & ja \\
\hline BT4 & 2016.02 & nov 2016 & QPH083BT & PAK & benzo(ghi)peryleen & $\mu \mathrm{g} / \mathrm{kg}$ & 1.9 & Satisfactory & Quasimeme & ja \\
\hline BT4 & 2016.02 & nov 2016 & QPH083BT & PAK & Benzo(k)fluoranteen & $\mu \mathrm{g} / \mathrm{kg}$ & 1.6 & Satisfactory & Quasimeme & ja \\
\hline BT4 & 2016.02 & nov 2016 & QPH084BT & PAK & Benzo(k)fluoranteen & $\mu \mathrm{g} / \mathrm{kg}$ & 1.9 & Satisfactory & Quasimeme & ja \\
\hline BT4 & 2016.02 & nov 2016 & QPH083BT & PAK & Chryseen & $\mu \mathrm{g} / \mathrm{kg}$ & 1 & Satisfactory & Quasimeme & ja \\
\hline BT4 & 2016.02 & nov 2016 & QPH084BT & PAK & Chryseen & $\mu \mathrm{g} / \mathrm{kg}$ & 1.7 & Satisfactory & Quasimeme & ja \\
\hline BT4 & 2016.02 & nov 2016 & QPH083BT & PAK & Dibenz(ah)antraceen & $\mu \mathrm{g} / \mathrm{kg}$ & 2.5 & Questionable & Quasimeme & ja \\
\hline BT4 & 2016.02 & nov 2016 & QPH084BT & PAK & Dibenz(ah)antraceen & $\mu \mathrm{g} / \mathrm{kg}$ & 3.5 & Unsatisfactory & Quasimeme & ja \\
\hline BT4 & 2016.02 & nov 2016 & QPH084BT & PAK & Fenantreen & $\mu \mathrm{g} / \mathrm{kg}$ & 2.2 & Questionable & Quasimeme & ja \\
\hline BT4 & 2016.02 & nov 2016 & QPH083BT & PAK & Fluoranteen & $\mu \mathrm{g} / \mathrm{kg}$ & 1.1 & Satisfactory & Quasimeme & ja \\
\hline BT4 & 2016.02 & nov 2016 & QPH084BT & PAK & Fluoranteen & $\mu \mathrm{g} / \mathrm{kg}$ & 0.9 & Satisfactory & Quasimeme & ja \\
\hline BT4 & 2016.02 & nov 2016 & QPH083BT & PAK & Fluoreen & $\mu \mathrm{g} / \mathrm{kg}$ & 0.6 & Satisfactory & Quasimeme & ja \\
\hline BT4 & 2016.02 & nov 2016 & QPH084BT & PAK & Fluoreen & $\mu \mathrm{g} / \mathrm{kg}$ & 0.8 & Satisfactory & Quasimeme & ja \\
\hline BT4 & 2016.02 & nov 2016 & QPH083BT & PAK & Indeno(123)peryleen & $\mu \mathrm{g} / \mathrm{kg}$ & 3.2 & Unsatisfactory & Quasimeme & ja \\
\hline BT4 & 2016.02 & nov 2016 & QPH084BT & PAK & Indeno(123)peryleen & $\mu \mathrm{g} / \mathrm{kg}$ & 2.5 & Questionable & Quasimeme & ja \\
\hline BT4 & 2016.02 & nov 2016 & QPH083BT & PAK & Pyreen & $\mu \mathrm{g} / \mathrm{kg}$ & 2.1 & Questionable & Quasimeme & ja \\
\hline BT4 & 2016.02 & nov 2016 & QPH084BT & PAK & Pyreen & $\mu \mathrm{g} / \mathrm{kg}$ & 1.6 & Satisfactory & Quasimeme & ja \\
\hline BT4 & 2017.02 & nov 2017 & QPH087BT & PAK & Acenafteen & $\mu \mathrm{g} / \mathrm{kg}$ & -1.8 & Satisfactory & WMR & ja \\
\hline BT4 & 2017.02 & nov 2017 & QPH088BT & PAK & Acenafteen & $\mu \mathrm{g} / \mathrm{kg}$ & 2.0 & Satisfactory & WMR & ja \\
\hline BT4 & 2017.02 & nov 2017 & QPH087BT & PAK & Antraceen & $\mu \mathrm{g} / \mathrm{kg}$ & -0.45 & Satisfactory & WMR & ja \\
\hline BT4 & 2017.02 & nov 2017 & QPH088BT & PAK & Antraceen & $\mu \mathrm{g} / \mathrm{kg}$ & -0.98 & Satisfactory & WMR & ja \\
\hline BT4 & 2017.02 & nov 2017 & QPH087BT & PAK & Benzo(a)antraceen & $\mu \mathrm{g} / \mathrm{kg}$ & 0.64 & Satisfactory & WMR & ja \\
\hline BT4 & 2017.02 & nov 2017 & QPH088BT & PAK & Benzo(a)antraceen & $\mu \mathrm{g} / \mathrm{kg}$ & 2.5 & Questionable & WMR & ja \\
\hline BT4 & 2017.02 & nov 2017 & QPH088BT & PAK & Benzo(a)pyreen & $\mu \mathrm{g} / \mathrm{kg}$ & 0.90 & Satisfactory & WMR & ja \\
\hline BT4 & 2017.02 & nov 2017 & QPH087BT & PAK & Benzo(b)fluoranteen & $\mu \mathrm{g} / \mathrm{kg}$ & 0.10 & Satisfactory & WMR & ja \\
\hline BT4 & 2017.02 & nov 2017 & QPH088BT & PAK & Benzo(b)fluoranteen & $\mu \mathrm{g} / \mathrm{kg}$ & 1.4 & Satisfactory & WMR & ja \\
\hline BT4 & 2017.02 & nov 2017 & QPH088BT & PAK & Benzo(ghi)peryleen & $\mu \mathrm{g} / \mathrm{kg}$ & 0.29 & Satisfactory & WMR & ja \\
\hline BT4 & 2017.02 & nov 2017 & QPH088BT & PAK & Benzo(k)fluoranteen & $\mu \mathrm{g} / \mathrm{kg}$ & 2.3 & Questionable & WMR & ja \\
\hline BT4 & 2017.02 & nov 2017 & QPH087BT & PAK & Chryseen & $\mu \mathrm{g} / \mathrm{kg}$ & -0.33 & Satisfactory & WMR & ja \\
\hline BT4 & 2017.02 & nov 2017 & QPH088BT & PAK & Chryseen & $\mu \mathrm{g} / \mathrm{kg}$ & 1.2 & Satisfactory & WMR & ja \\
\hline BT4 & 2017.02 & nov 2017 & QPH088BT & PAK & Dibenz(ah)antraceen & $\mu \mathrm{g} / \mathrm{kg}$ & 2.4 & Questionable & WMR & nee \\
\hline BT4 & 2017.02 & nov 2017 & QPH087BT & PAK & Fenantreen & $\mu \mathrm{g} / \mathrm{kg}$ & 3.0 & Questionable & WMR & ja \\
\hline BT4 & 2017.02 & nov 2017 & QPH088BT & PAK & Fenantreen & $\mu \mathrm{g} / \mathrm{kg}$ & 2.4 & Questionable & WMR & ja \\
\hline BT4 & 2017.02 & nov 2017 & QPH087BT & PAK & Fluoranteen & $\mu \mathrm{g} / \mathrm{kg}$ & 0.51 & Satisfactory & WMR & ja \\
\hline BT4 & 2017.02 & nov 2017 & QPH088BT & PAK & Fluoranteen & $\mu \mathrm{g} / \mathrm{kg}$ & 0.35 & Satisfactory & WMR & ja \\
\hline BT4 & 2017.02 & nov 2017 & QPH087BT & PAK & Fluoreen & $\mu \mathrm{g} / \mathrm{kg}$ & -2.2 & Questionable & WMR & ja \\
\hline BT4 & 2017.02 & nov 2017 & QPH088BT & PAK & Fluoreen & $\mu \mathrm{g} / \mathrm{kg}$ & 0.12 & Satisfactory & WMR & ja \\
\hline BT4 & 2017.02 & nov 2017 & QPH088BT & PAK & Indeno(123)peryleen & $\mu \mathrm{g} / \mathrm{kg}$ & 0.87 & Satisfactory & WMR & ja \\
\hline BT4 & 2017.02 & nov 2017 & QPH087BT & PAK & Pyreen & $\mu \mathrm{g} / \mathrm{kg}$ & -1.3 & Satisfactory & WMR & ja \\
\hline BT4 & 2017.02 & nov 2017 & QPH088BT & PAK & Pyreen & $\mu \mathrm{g} / \mathrm{kg}$ & 0.95 & Satisfactory & WMR & ja \\
\hline
\end{tabular}


ABM Schelpdieren zoet 2017 / Bijlage 4.3: Validatiegegevens analysemethoden

\section{Rapportagegrenzen en meetonzekerheid}

\begin{tabular}{|l|l|c|c|c|c|c|c|}
\hline Groep & Component & $\begin{array}{c}\text { rapportage- } \\
\text { grens }\end{array}$ & $\begin{array}{c}\text { detectie- } \\
\text { limiet }\end{array}$ & eenheid & vc & $\mathbf{n}$ & $\boldsymbol{d}_{\mathbf{c}}$ \\
\hline PAK & Acenafteen & 0.13 & 0.07 & $\mu \mathrm{g} / \mathrm{kg}$ & 23.4 & 20 & 0 \\
\hline PAK & Antraceen & 0.13 & 0.07 & $\mu \mathrm{g} / \mathrm{kg}$ & 30.7 & 28 & 0 \\
\hline PAK & Benzo(a)antraceen & 0.13 & 0.07 & $\mu \mathrm{g} / \mathrm{kg}$ & 21.2 & 35 & 0 \\
\hline PAK & Benzo(a)pyreen & 0.13 & 0.07 & $\mu \mathrm{g} / \mathrm{kg}$ & 16.8 & 34 & 0 \\
\hline PAK & Benzo(b)fluoranteen & 0.13 & 0.07 & $\mu \mathrm{g} / \mathrm{kg}$ & 21.4 & 42 & 0 \\
\hline PAK & benzo(ghi)peryleen & 0.13 & 0.07 & $\mu \mathrm{g} / \mathrm{kg}$ & 22.0 & 36 & 0 \\
\hline PAK & Benzo(k)fluoranteen & 0.13 & 0.07 & $\mu \mathrm{g} / \mathrm{kg}$ & 23.0 & 32 & 0 \\
\hline PAK & Chryseen & 0.33 & 0.17 & $\mu \mathrm{g} / \mathrm{kg}$ & 19.9 & 37 & 0 \\
\hline PAK & Dibenz(ah)antraceen & 0.33 & 0.17 & $\mu \mathrm{g} / \mathrm{kg}$ & 30.6 & 9 & 0 \\
\hline PAK & Fenantreen & 1.80 & 0.90 & $\mu \mathrm{g} / \mathrm{kg}$ & 17.8 & 20 & 0 \\
\hline PAK & Fluoranteen & 0.85 & 0.43 & $\mu \mathrm{g} / \mathrm{kg}$ & 13.6 & 39 & 0 \\
\hline PAK & Fluoreen & 0.20 & 0.10 & $\mu \mathrm{g} / \mathrm{kg}$ & 19.6 & 31 & 0 \\
\hline PAK & Indeno(123)peryleen & 0.13 & 0.07 & $\mu \mathrm{g} / \mathrm{kg}$ & 28.3 & 26 & 0 \\
\hline PAK & Pyreen & 0.72 & 0.36 & $\mu \mathrm{g} / \mathrm{kg}$ & 13.0 & 42 & 0 \\
\hline- & Dry-weight & 0.3 & 0.15 & $\%$ & 3.5 & 50 & 0 \\
\hline- & Ash-Weight & 0.12 & 0.06 & $\%$ & 9.0 & 31 & 0 \\
\hline- & Total-Lipid & 0.2 & 0.1 & $\%$ & 16.6 & 39 & 0 \\
\hline
\end{tabular}

verwaarloosbaar klein

$\mathrm{n}=$ aantal ringonderzoeken aan de hand waarvan een Z-score bepaald kon worden

$d_{\mathrm{c}}=$ gecombineerde constante fout in de eenheid van de concentratie van de component 
Wageningen Marine Research

T: +31(0)317480900

E: marine-research@wur.nl

www.wur.nl/marine-research

Visitors address

- Ankerpark 271781 AG Den Helder

- Korringaweg 7, 4401 NT Yerseke

- Haringkade 1, 1976 CP IJmuiden
Wageningen Marine Research is the Netherlands research institute established to provide the scientific support that is essential for developing policies and innovation in respect of the marine environment, fishery activities, aquaculture and the maritime sector.

Wageningen University \& Research is specialised in the domain of healthy food and living environment.

The Wageningen Marine Research vision:

'To explore the potential of marine nature to improve the quality of life.'

The Wageningen Marine Research mission

- To conduct research with the aim of acquiring knowledge and offering advice on the sustainable management and use of marine and coastal areas.

- Wageningen Marine Research is an independent, leading scientific research institute.

Wageningen Marine Research is part of the international knowledge organisation Wageningen UR (University \& Research centre). Within Wageningen UR, nine specialised research institutes of Stichting Wageningen Research (a Foundation) have joined forces with Wageningen University to help answer the most important questions in the domain of healthy food and living environment. 